\title{
Editorial NorDiNa 3/2021
}

\author{
Welcome to the third issue of NorDiNa in 2021!
}

Socioscientific issues (SSI) is the area that Louise Rietz, Anders Jönsson and Mats Lundström investigate in their article "Students' use of justifications in socioscientific argumentation". The study concerns upper secondary students in chemistry education. Written argumentation was gathered during an SSI-intervention aiming at developing high quality argumentation focussing on per- and polyfluoroalkyl (PFAS) substances in everyday products. The analysis made use of previous research and focused on content knowledge and value-based justifications. The results show that content knowledgebased justifications were common while value-based justifications were less common. A new category emerged: reasoning, where students draw conclusions, make conditions, and make predictions about the future. The study suggests that specific teaching about high quality argumentation should be part of the teacher education.

Claudia Melis and Per-Arvid Wold's article is entitled "Kindergarten student teachers' knowledge regarding crucial environmental challenges". Their study investigates the understanding regarding the mechanisms underlying global climate change and pollination by conducting a survey of Norwegian kindergarten student teachers, at the beginning of the academic year, and by asking follow-up questions after the course in Natural Sciences. The authors argue that their results can be interpreted in the light of constructivist learning theory and might partly be explained by the role mass media play in influencing scientific literacy. For future citizens to make informed decisions, ecological issues should be prioritised in education.

In their article "Pre-service science teachers' and in-service physics teachers' views on the knowledge and skills of a good teacher" Thomas Frågåt, Ellen Henriksen and Cathrine Tellefsen investigate how science teachers conceptualise their professional qualities. The authors asked first and final-year preservice science teachers and in-service physics teachers to describe the knowledge and skills needed to be a good science/physics teacher. Data was collected through a one-item questionnaire, followed by interviews. It was found that all respondent groups emphasised science content knowledge as important. In-service teachers also often described external factors such as working conditions. Firstyear pre-service teachers put more emphasis on pedagogical skills and personality traits, whereas final-year pre-service teachers expressed a more integrated view of science teacher knowledge and skills. The authors discuss the need for teacher education to focus on integrating science content knowledge and pedagogical knowledge through articulating aspects of PCK, and on giving pre- and in-service teachers arenas for professional development and for research-based discussions of teaching and learning.

The article "Scientific practices- towards a common understanding" written by Berit S. Haug, Øystein Sørborg, Sonja M. Mork and Merethe Frøyland aims at contributing to a common understanding of what scientific practices are and how they can be implemented and assessed in the classroom. The study is grounded in the Norwegian curriculum, LK20, and concludes that teachers are mainly left on 
their own in how to interpret, implement and assess scientific practices. In order to start a discussion and give guidance, the authors developed a model that demonstrates the dynamic relationship between the practices. The model, with figures, can be used directly in teaching as a tool to give students (and teachers) a meta-perspective on their own work by looking at what they have done, why they have done it, and how this relates to past and future work.

The article by Anne Pellikka, Sonja Lutovac and Raimo Kaasila is entitled "Relationships between pre-service primary teachers' beliefs, understandings, and planning of inquiry-based teaching in biology education". The authors state that these relationships have been researched separately in earlier studies. They argue that exploring them simultaneously allows a greater insight into the process of teacher change and professional development. Drawing on the narrative method, data included learning diaries, lesson plans, and interviews. The authors discuss the relationships in the light of their impact on teacher change and professional development and provide suggestions for teacher education.

Dag Atle Lysne and Bjørn Tore Esjeholm's article "How do teachers communicate with students in technology projects?" analyzes the communication between teachers and students in six technology projects. The main pattern is that teachers act instructively to students or try to convince them to use a solution the teacher has planned in advance. Exploratory and moderating communication were less frequent. This is contrary to the intention of inquiry-based methods. However, discussion of conceptual topics seems to provide a more exploratory approach from teachers compared to procedural topics. Likewise, active students, who themselves try to come up with solutions to the challenges, seem to contribute to a more exploratory approach from the teachers. The same goes for tasks that are so open that teachers will not be able to plan for solutions in advance. No school scientific concepts in natural science were used in the discussions between teachers and students.

This issue also includes a presentation of Mari Sjøberg's recent dissertation.

This is the last issue in which Carl-Johan Rundgren is involved as editor. Carl-Johan wants to thank NorDiNa's authors, reviewers and readers for their contributions the last eight years. The editorial team wants to thank Carl-Johan for his important contribution to the development of NorDiNa. During Carl-Johan's time as editor the journal has further developed as an important, and high quality, publication channel in science education. During these years the journal has also been significantly modernized by the digitalization of journal processes. Carl-Johan has played an important and central role in this developmental work. The editorial team wants to thank Carl-Johan for a very pleasant, fruitful, and flexible collaboration.

We hope you enjoy your reading,

Clas Olander, Are Turmo \& Carl-Johan Rundgren

Editors of NorDiNa 


\section{NorDiNa - Nordic Studies in Science Education}

\section{Editor in chief}

Merethe Frøyland (The Norwegian Centre for Science Education, University of Oslo).

\section{Main Editors}

Are Turmo (University of Oslo, Norway)

Carl-Johan Rundgren (Stockholm University, Sweden)

Clas Olander, (Malmö University, Sweden)

\section{National Co-Editors}

Antti Laherto (University of Helsinki, Finland)

Marianne Achiam (University of Copenhagen, Denmark)

Auður Pálsdóttir (University of Iceland, Iceland)

\section{Editorial board}

Svein Sjøberg (University of Oslo, Norway)

Anita Wallin (University of Gothenburg, Sweden)

Per-Olof Wickman (Stockholm University, Sweden)

Marianne Ødegaard (University of Oslo, Norway)

Allyson Macdonald (University of Iceland, Iceland)

Jari Lavonen (University of Helsinki, Finland)

Irmeli E. Palmberg (Åbo Akademi University, Finland)

Rie Popp Troelsen (University of Southern Denmark, Denmark)

Stein Dankert Kolstø (University of Bergen, Norway)

Christina Ottander (Umeå University, Sweden)

Maija Aksela (University of Helsinki, Finland)

Birgitte Lund Nielsen (Aarhus University, Denmark)

Lars Brian Krogh (VIA University College, Denmark)

\section{Open Access Journal}

NorDiNa is available as an Open Access Journal at the following URL: www.journals.uio.no/ index.php/nordina/index. The editors encourage authors and referees to register at NorDiNas Internet site. In case of problems when register or submitting papers, please contact the editors. Nordic Studies in Science Education do not charge any fee for publication. 